\title{
Short term sequelae of preeclampsia: a single center cohort study
}

\author{
Michael Girsberger ${ }^{*^{*}}$ D, Catherine Muff², Irene Hösli and Michael Jan Dickenmann ${ }^{1}$
}

\begin{abstract}
Background: Data on the prevalence of persistent symptoms in the first year after preeclampsia are limited. Furthermore, possible risk factors for these sequelae are poorly defined. We investigated kidney function, blood pressure, proteinuria and urine sediment in women with preeclampsia 6 months after delivery with secondary analysis for possible associated clinical characteristics.
\end{abstract}

Methods: From January 2007 to July 2014 all women with preeclampsia and 6-months follow up at the University Hospital Basel were analyzed. Preeclampsia was defined as new onset of hypertension $(\geq 140 / 90 \mathrm{mmHg})$ and either proteinuria or signs of end-organ dysfunction. Hypertension was defined as a blood pressure $\geq 140 / 90 \mathrm{mmHg}$ or the use of antihypertensive medication. Proteinuria was defined as a protein-to-creatinine ratio in a spot urine $>11 \mathrm{mg} / \mathrm{mmol}$. Urine sediment was evaluated by a nephrologist. Secondary analyses were performed to investigate for possible parameters associated with persistent symptoms after preeclampsia.

Results: Two hundred two women were included into the analysis. At a mean time of follow up of 172 days $(+/-39.6)$ after delivery, mean blood pressure was $124 / 76 \mathrm{mmHg}(+/-14 / 11$, range 116-182/63-110) and the mean serum-creatinine was $61.8 \mu \mathrm{mol} / \mathrm{l}(33-105 \mu \mathrm{mol} / \mathrm{l})(\mathrm{normal}<110 \mu \mathrm{mol} / \mathrm{l})$. Mean estimated glomerular filtration rate using CKD-EPI was $110.7 \mathrm{mml} / \mathrm{min} / 1.73 \mathrm{~m}^{2}$ (range $59.7-142.4 \mathrm{mml} / \mathrm{min} / 1.73 \mathrm{~m}^{2}$ ) (normal $>60 \mathrm{mml} / \mathrm{min} / 1.73 \mathrm{~m}^{2}$ ). $20.3 \%(41 / 202)$ had a blood pressure of $140 / 90 \mathrm{mmHg}$ or higher (mean 143/89 $\mathrm{mmHg}$ ) or were receiving antihypertensive medication (5.5\%, 11/202). Proteinuria was present in 33.1\% (66/199) (mean $27.5 \mathrm{mg} / \mathrm{mmol}$ ). Proteinuria and hypertension was present in $8 \%$ (16/199). No active urine sediment (e.g. signs of glomerulonephritis) was observed. Age and gestational diabetes were associated with persistent proteinuria and severe preeclampsia with eGFR decline of $\geq 10 \mathrm{ml} / \mathrm{min} / 1.73 \mathrm{~m}^{2}$.

Conclusion: Hypertension and proteinuria are common after 6 months underlining the importance of close follow up to identify those women who need further care.

Keywords: Preeclampsia, Follow-up, Sequelae

\section{Background}

Preeclampsia is a pregnancy related disease defined as new onset of hypertension and either proteinuria or signs of other end-organ dysfunction (e.g. hepatic abnormality, pulmonary edema, thrombocytopenia). Preeclampsia occurs in approximately $5 \%$ of pregnancies [1], and is therefore a frequent disorder complicating gestation. Apart from the high morbidity with sometimes even lifethreatening implications for mother and child during the acute phase of the disease, there are also concerns about

\footnotetext{
* Correspondence: mgirsberger@hotmail.com

${ }^{1}$ Clinic for Transplantation Immunology and Nephrology, University Hospital Basel, Petersgraben 4, 4031 Basel, Switzerland

Full list of author information is available at the end of the article
}

long-term sequelae. Studies in the past have shown an increased risk of kidney biopsy [2] indicating kidney disease or end-stage renal failure $[3,4]$. There is also evidence of increased risk of chronic hypertension following an episode of preeclampsia [5-7].

To identify those with chronic hypertension or proteinuria after delivery, it is important to know the usual time of resolution of these symptoms. Guidelines state that blood pressure should normalize in the first 3 months [8] and referral is considered if hypertension or proteinuria persists after three to 6 months $[9,10]$. However, there is data indicating that hypertension persists in almost $40 \%$ of patients after 3 months and still is

(c) The Author(s). 2018 Open Access This article is distributed under the terms of the Creative Commons Attribution 4.0 International License (http://creativecommons.org/licenses/by/4.0/), which permits unrestricted use, distribution, and 
present in $18 \%$ after 2 years [11]. In one study almost $29 \%$ of patients were hypertensive after 5 years, although sample size was small [12]. Therefore, the time to define chronicity of symptoms remains unclear. In regard to the few existing studies, we hypothesized that a significant part of patients still show sequelae of preeclampsia 6 months after pregnancy. The aim of the study was to determine the frequency of hypertension, proteinuria and eGFR (estimated glomerular filtration rate) decline 6 months after preeclampsia and to search for possible parameters associated with these endpoints.

\section{Methods}

From January 2007 to July 2014 all women with preeclampsia at the University Hospital Basel referred to our nephrology clinic were included into the study. As by our hospital policy, all patients with preeclampsia are referred for nephrology follow-up after 6 months. Patients were closely followed by their family doctor or obstetrician and referred earlier if necessary. Preeclampsia was defined as new onset of hypertension $(\geq 140 / 90 \mathrm{mmHg})$ after the 20th gestational week or worsening hypertension (defined as blood pressure values $\geq 20 / 10 \mathrm{mmHg}$ higher than previously measured during pregnancy) in patients with preexisting elevated blood pressure and either proteinuria or other signs of end-organ dysfunction. The gynaecology department of the University Hospital of Basel had been in the practice of defining preeclampsia without the proteinuria requirement, as was later confirmed by the ACOG 2013 guidelines [13]. Hypertension was defined as a blood pressure $\geq 140 / 90 \mathrm{mmHg}$ or the use of antihypertensive medication. This definition was used for inclusion into the study as well as at follow up. The presence of severe hypertension $(\geq 160 / 110 \mathrm{mmHg})$, acute renal failure or oliguria, eclamptic seizure, pulmonary lung oedema, signs of HELLP-Syndrome, hyperreflexia, severe headaches, visual disturbances or intra uterine growth retardation with or without pathological Doppler ultrasound resulted in a diagnosis of severe preeclampsia [14]. Acute kidney injury was defined as a rise in serum creatinine concentration of more than $50 \%$ from baseline during hospitalisation. The presence of pre-existing conditions like hypertension, diabetes mellitus or kidney disease was gathered from medical records. Proteinuria was defined as a protein-to-creatinine ratio in a spot urine $>11 \mathrm{mg} / \mathrm{mmol}$ [15]. Decline of kidney function was defined as a decrease in eGFR $\geq 10 \mathrm{ml} / \mathrm{min} / 1.73 \mathrm{~m}^{2}$. Urine sediments were evaluated by a staff nephrologist. For secondary analyses, a multivariate logistic regression model was applied. Univariate analysis was conducted in all variables with at least 15 observations and variables with a $p$-value $<0.2$ were added to the model. Wilcoxon Mann Whitney test was used to compare medians due to skewed distribution of the baseline characteristics in the subgroups; chi- squared test was used to compare frequencies. Different denominators in the results section are due to missing data in a few patients.

\section{Results}

Of the 225 women referred to our nephrology clinic, 23 were lost to follow-up (10\%). Two hundred two were included in the analysis. The mean time of the follow up visit was 172 days $(+/-39.6)$ after delivery. Mean age of the 202 women was 32 years (18-45 years). 58.2\% $(117 / 201)$ were pregnant for the first time (primigravida). In $22.2 \%(43 / 194)$ of the patient's preeclampsia occurred before 34 weeks of gestation. Severe preeclampsia was observed in 67\% (132/197) and eclampsia as the most severe form was seen in $2 \%(4 / 198)$. $90.1 \%$ $(181 / 201)$ had no pre-existing diseases before pregnancy (diabetes mellitus, chronic kidney disease or hypertension). Baseline characteristics are shown in Table 1.

Distribution of blood pressure and urinary protein excretion at follow-up are shown in Fig. 1a and b. The mean blood pressure at 6-months follow up was $124 / 76 \mathrm{mmHg}$ $(+/-14 / 11$, range $116-182 / 63-110)$ and the mean serum-creatinine was $61.8 \mu \mathrm{mol} / \mathrm{l}(33-105 \mu \mathrm{mol} / \mathrm{l})$ (normal < $110 \mu \mathrm{mol} / \mathrm{l})$. Mean estimated glomerular filtration rate (eGFR) using CKD-EPI (chronic kidney disease epidemiology collaboration) was $110.7 \mathrm{ml} / \mathrm{min} /$ $1.73 \mathrm{~m}^{2}\left(59.7-142.4 \mathrm{ml} / \mathrm{min} / 1.73 \mathrm{~m}^{2}\right.$ ) (normal $>60 \mathrm{mml} /$ $\left.\min / 1.73 \mathrm{~m}^{2}\right) .20 .3 \%(41 / 202)$ had a blood pressure of $140 / 90 \mathrm{mmHg}$ or higher (mean $143 / 89 \mathrm{mmHg}$ ) or received antihypertensive medication $(5.5 \%, 11 / 202)$. Proteinuria was present in $33.1 \%$ (66/199) (mean $27.5 \mathrm{mg} / \mathrm{mmol}$, range $12-261 \mathrm{mg} / \mathrm{mmol}$ ). Proteinuria and hypertension were present in $8 \%(16 / 199)$ (Fig. 2). $54.3 \%(108 / 199)$ had none of the investigated sequelae at follow up. No active urine sediment (e.g. glomerular

Table 1 Baseline characteristics

\begin{tabular}{ll}
\hline Age mean ( \pm SD) & $32( \pm 5.9)$ \\
$\begin{array}{l}\text { Onset of preeclampsia (gestational week) } \\
\text { mean ( } \pm \text { SD) }\end{array}$ & $36+3( \pm 3.9$ weeks) \\
Early Onset (<34 weeks of gestation) (43/195) & $22.1 \%$ \\
Nulliparous (150/199) & $75.4 \%$ \\
Multiple pregnancy (twins, triplets) (27/202) & $13.4 \%$ \\
In vitro fertilisation (13/202) & $6.4 \%$ \\
Diabetes before pregnancy (4/201) & $1.99 \%$ \\
Gestational diabetes (19/202) & $9.4 \%$ \\
Previous hypertension (16/202) & $7.9 \%$ \\
HELLP (41/198) & $20.7 \%$ \\
Eclampsia (4/198) & $2.0 \%$ \\
Severe preeclampsia (132/197) & $67 \%$ \\
Acute kidney injury (17/197) & $8.6 \%$ \\
Chronic kidney disease (4/201) & $1.99 \%$ \\
\hline
\end{tabular}


a urinary protein excretion

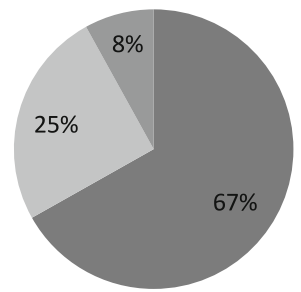

$\leq 11 \mathrm{mg} / \mathrm{mmol}$

$11-29 \mathrm{mg} / \mathrm{mmol}$

$\geq 30 \mathrm{mg} / \mathrm{mmol}$ b blood pressure

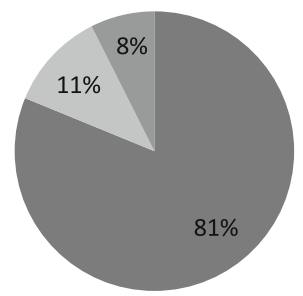

- $<140 / 90 \mathrm{mmHg}$

140/90-149/99

$\mathrm{mmHg}$

—150/100 mmHg

Fig. $1 \mathbf{a}$ and $\mathbf{b}$ Distribution of urinary protein excretion and blood pressure at follow-up

microhematuria, casts, signs of glomerulonephritis) was observed.

Baseline characteristics in women with sequelae at follow-up are shown in Tables 2, 3 and 4. Multivariate logistic regression analyses showed an association of age and gestational diabetes with proteinuria $>11 \mathrm{mg} / \mathrm{mmol}$ and proteinuria $\geq 30 \mathrm{mg} / \mathrm{mmol}$ at follow-up, respectively. Additionally, severe preeclampsia was associated with an eGFR decline $\geq 10 \mathrm{ml} / \mathrm{min} / 1.73 \mathrm{~m}^{2}$. None of the investigated parameters were associated with persistent hypertension (Table 5).

\section{Discussion}

Persistent proteinuria and hypertension after preeclampsia have been reported in several studies. Proteinuria in the first few months after preeclampsia is common $[11,16,17]$, and can be detected up to several years. Hypertension can also persist for months and even for years $[11,12,18]$. Decreased kidney function is uncommon even after short term follow up in contrast to persistent hypertension and proteinuria [4, 12, 16, 19]. However, there is data indicating that the risk of chronic kidney disease after preeclampsia might be increased later in life [2-4]. To our knowledge, our study is the largest on short term sequelae after preeclampsia. It shows that a significant part of patients with preeclampsia have ongoing sequelae 6 months after delivery. 20\% remain hypertensive and one third have persistent proteinuria. $8 \%$ have combined hypertension and proteinuria. If hypertension or proteinuria persists 6 months after delivery, different guidelines state that referral for internal medicine or nephrology and further diagnostics should be considered $[9,10]$.

Berks et al. [11] reported proteinuria in $14 \%$ of patients after 3 months and $8 \%$ after 2 years. When applying, a proteinuria cut off of $0.3 \mathrm{~g} / \mathrm{d}$ as done by this group, proteinuria was present in $8 \%$ in our study after 6 months, which is consistent with the $14 \%$ after 3 months in Berks' study. However, Berks et al. measured proteinuria by $24-\mathrm{h}$ urine collection, whereas a creatinine-protein ratio to estimate proteinuria was used in this study, which makes a direct comparison of this low range proteinuria results more difficult. In a study by Chua et al. [20], proteinuria was absent after 3 months, but a relatively high cut off of $0.5 \mathrm{~g} / 24 \mathrm{~h}$ was used. Again, proteinuria was measured with 24-h urine

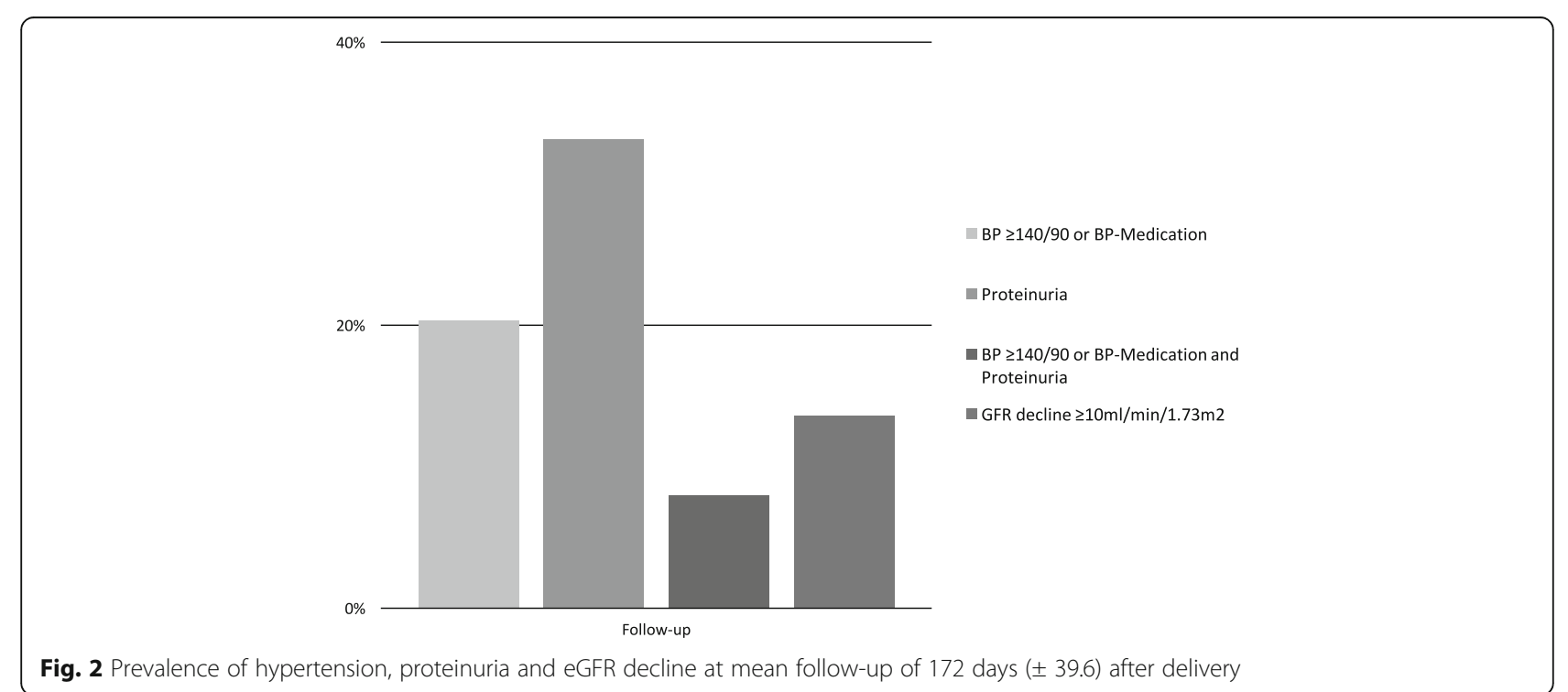


Table 2 Baseline characteristics (median (IQR)) of women with hypertension at follow-up

\begin{tabular}{lllllll}
\hline & No HT $(n=164)$ & BP $\geq 140 / 90(n=38)$ & $p$-value & No HT $(n=187)$ & BP $\geq 150 / 100(n=15)$ & $p$-value \\
\hline Age & $32(28-36)$ & $34(30-37)$ & 0.16 & $32(28-36)$ & $32(29-40)$ & 0.59 \\
Onset (d) & $260(241-274)$ & $250(233-267)$ & 0.08 & $259(241-273)$ & $250(217-263)$ & 0.12 \\
Early onset & $20.3 \%(32 / 158)$ & $29.7 \%(11 / 37)$ & 0.21 & $21.1 \%(38 / 180)$ & $33.3 \%(5 / 15)$ & 0.27 \\
Nulliparous & $75.6 \%(124 / 162)$ & $68 \%(26 / 38)$ & 0.30 & $75.1 \%(139 / 185)$ & $73.3 \%(11 / 15)$ & 0.88 \\
Time to f/u (d) & $180(155-191)$ & $182(132-190)$ & 0.33 & $180(153-191)$ & $176(121-187)$ & 0.18 \\
MP & $14.0 \%(23 / 164)$ & $10.5 \%(4 / 38)$ & 0.57 & $14.4 \%(27 / 187)$ & $0 \%(0 / 15)$ & 0.11 \\
IVF & $6.7 \%(11 / 164)$ & $5.7 \%(2 / 38)$ & 0.74 & $7.0 \%(13 / 187)$ & $0 \%(0 / 15)$ & 0.29 \\
GD & $7.9 \%(13 / 164)$ & $15.8 \%(6 / 38)$ & 0.13 & $9.1 \%(17 / 187)$ & $13.3 \%(2 / 15)$ & 0.56 \\
HELLP & $21.9 \%(35 / 160)$ & $15.8 \%(6 / 38)$ & 0.40 & $21.9 \% 40 / 183$ & $6.7 \%(1 / 15)$ & 0.16 \\
Severe PE & $67.3 \%(107 / 159)$ & $64.1 \%(25 / 39)$ & 0.86 & $67.0 \%(122 / 182)$ & $66.7 \%(10 / 15)$ & 0.97 \\
AKI & $9.7 \%(14 / 145)$ & $5.3 \%(3 / 38)$ & 0.86 & $7.7 \%(14 / 182)$ & $20.0 \% 3 / 15$ & 0.10 \\
\hline
\end{tabular}

$H T$ Hypertension, BP Blood pressure in $\mathrm{mmHg}, P E$ Preeclampsia, AKI Acute kidney injury, GD gestational diabetes; $f / u$ follow-up, $d$ days

collection. Another study reported persistent Microalbuminuria in up to $60 \%$ of patients $2-4$ months after preeclampsia and in still $40 \%$ after $3-5$ years using a considerably low cut off for microalbuminuria of $14 \mathrm{mg} / 24 \mathrm{~h}$ [19]. Overall, despite conflicting evidence proteinuria seems to be a relevant short-term sequela after preeclampsia. In our secondary analysis, older age at baseline was associated with proteinuria $>11 \mathrm{mg} / \mathrm{mmol}$, but not with proteinuria $>30 \mathrm{mg} / \mathrm{mmol}$. Gestational diabetes was associated with proteinuria $>30 \mathrm{mg} / \mathrm{mmol}$. However, given the large confidence interval with the lower range close to 1 , this finding might be significant by chance. Furthermore, as we know from diabetic kidney disease, it usually takes years of abnormal glucose metabolism to result in kidney damage with proteinuria, making this finding also clinically unlikely.

In our study, $20 \%$ of women were hypertensive after 6 months. In the study by Berks et al., 39\% of women had hypertensive blood pressure values after 3 months and $18 \%$ were still hypertensive after 2 years [11]. These findings suggest that there is no further resolution of hypertension after 6 months in contrast to proteinuria which was only present in $2 \%$ after 2 years. Another explanation might be the difference in severe preeclampsia of $67 \%$ in our study to $89 \%$ in the study by Berks et al. and thereby a faster resolution of symptoms in our study. In another study from Japan [16] 17\% (9/52) of women with preeclampsia still had hypertensive blood pressure values or received antihypertensive medication after 2 years. This value is close to the $18 \%$ of women with hypertension after 2 years in the study by Berks et al., although the percentage of patients with severe preeclampsia was not reported in the Japanese study. In a third study from Iran [12], 29\% (10/35) were still hypertensive after a median follow up of 5.7 years. We could not identify any clinical parameters associated with persistent hypertension in our secondary analysis. In a subgroup analysis in 129 women with available data on peak hypertensive values at baseline, peak systolic blood pressure was significantly associated $(p=0.04)$ with

Table 3 Baseline characteristics (median (IQR)) of women with proteinuria at follow-up

\begin{tabular}{lllllll}
\hline & No UPE $(n=134)$ & UPE $>0.11(n=66)$ & $p$-value & No UPE $(n=184)$ & UPE $\geq 30(n=16)$ & $p$-value \\
\hline Age & $31(28-35)$ & $35(28-38)$ & 0.16 & $32(29-36)$ & $34(25-38)$ & 0.80 \\
Onset (d) & $260(238-272)$ & $258(246-272)$ & 0.61 & $259(240-272)$ & $266(248-279)$ & 0.29 \\
Early onset & $24.8 \%(32 / 129)$ & $14.1 \%(9 / 64)$ & 0.09 & $22.6 \%(40 / 177)$ & $6.25 \%(1 / 16)$ & 0.13 \\
Nulliparous & $75.2 \%(100 / 133)$ & $73.9 \%(48 / 65)$ & 0.84 & $73.6 \%(134 / 182)$ & $87.5 \%(14 / 16)$ & 0.22 \\
Time to f/u (d) & $183(157-191)$ & $172(138-187)$ & 0.06 & $180(154-190)$ & $160(114-195)$ & 0.42 \\
MP & $12.7 \%(17 / 134)$ & $15.2 \%(10 / 66)$ & 0.61 & $14.1 \%(26 / 184)$ & $6.3 \%(1 / 16)$ & $0.3 \%(1 / 16)$ \\
IVF & $4.5 \%(6 / 134)$ & $10.6 \%(7 / 66)$ & 0.10 & $6.5 \%(12 / 184)$ & 0.34 \\
GD & $7.5 \%(10 / 134)$ & $16.7 \%(9 / 66)$ & 0.16 & $8.2 \%(15 / 184)$ & $25.0 \%(4 / 16)$ \\
HELLP & $22.7 \%(30 / 132)$ & $16.9 \%(11 / 65)$ & 0.35 & $22.1 \%(40 / 181)$ & $6.3 \%(1 / 16)$ & 0.97 \\
Severe & $67.2 \%(88 / 131)$ & $66.2 \%(43 / 65)$ & 0.89 & $66.1 \%(119 / 180)$ & $75 \%(12 / 16)$ & 0.13 \\
AKI & $9.9 \%(13 / 131)$ & $6.2 \%(4 / 65)$ & 0.34 & $8.3 \%(15 / 180)$ & $12.5 \%(2 / 16)$ & 0.45 \\
\hline
\end{tabular}

UPE urinary protein excretion, HT Hypertension, BP Blood pressure in $\mathrm{mmHg}, P E$ Preeclampsia, AKI Acute kidney injury, GD gestational diabetes; $f / u$ follow-up; $d$ days 
Table 4 Baseline characteristics (median (IQR)) of women with decline in eGFR $\geq 10 \mathrm{ml} / \mathrm{min} / 1.73 \mathrm{~m} 2$ at follow-up

\begin{tabular}{llll}
\hline & No eGFR decline $(n=170)$ & eGFR decline $(n=27)$ & $p$-value \\
\hline Age & $33(28-37)$ & $31(27-35)$ & 0.20 \\
Onset (d) & $258(240-272)$ & $261(241-273)$ & 0.64 \\
Early onset & $21.8 \%(36 / 165)$ & $18.5 \%(5 / 27)$ & 0.70 \\
Nulliparous & $75.7 \%(128 / 169)$ & $66.7 \%(18 / 27)$ & 0.32 \\
Time to f/u (d) & $180(152-190)$ & $179(154-190)$ & 0.93 \\
MD & $15.3 \%(26 / 170)$ & $3.7 \%(1 / 27)$ & 0.10 \\
IVF & $7.7 \%(13 / 170)$ & $0 \%(0 / 27)$ & 0.14 \\
GD & $8.8 \%(15 / 170)$ & $14.8 \%(4 / 27)$ & 0.33 \\
HELLP & $21.2 \%(36 / 170)$ & $18.5 \%(5 / 27)$ & 0.75 \\
Severe PE & $70 \%(119 / 170)$ & $48.2 \%(13 / 27)$ & 0.03 \\
AKI & $10.1 \%(17 / 169)$ & $0 \%(0 / 27)$ & 0.09 \\
\hline
\end{tabular}

$H T$ Hypertension, BP Blood pressure in mmHg, PE Preeclampsia, AKI Acute kidney injury, GD gestational diabetes, f/u follow-up; $d$ days

Table 5 Multivariate logistic regression analysis for hypertension, proteinuria and eGFR at follow-up

\begin{tabular}{llll}
\hline & Odds ratio & $p$-value & $95 \%$ conf. \\
\hline BP $\geq 140 / 90 ~ m m H g$ & & & \\
Age & 1.05 & 0.18 & $0.98-1.12$ \\
Time to f/u (d) & 0.99 & 0.08 & $0.98-1.00$ \\
Onset (d) & 0.99 & 0.20 & $0.99-1.00$ \\
GD & 2.16 & 0.16 & $0.74-6.34$ \\
& & 0.06 & \\
BP $\geq 150 / 100 ~ m m H g$ & & & \\
Time to f/u (d) & 0.99 & 0.20 & $0.98-1.00$ \\
Onset (d) & 0.99 & 0.12 & $0.98-1.00$ \\
HELLP & 0.24 & 0.18 & $0.03-1.96$ \\
AKI & 2.7 & 0.17 & $0.65-11.23$ \\
& & 0.08 & \\
UPE $>11 \mathrm{mg} / \mathrm{mmol}$ & & & \\
Age & 1.06 & 0.03 & $1.01-1.13$ \\
GD & 1.71 & 0.21 & $0.70-4.81$ \\
Early onset & 0.46 & 0.09 & $0.21-1.11$ \\
& & 0.02 &
\end{tabular}

UPE $\geq 30 \mathrm{mg} / \mathrm{mmol}$

$\begin{array}{llll}\text { GD } & 3.67 & 0.049 & 1.01-13.37 \\ \text { HELLP } & 0.27 & 0.21 & 0.03-2.13 \\ \text { Early onset } & 0.35 & 0.45 & 0.02-5.46 \\ \text { Onset (d) } & 1.01 & 0.77 & 0.97-1.04 \\ & & 0.08 & \end{array}$

eGFR decline

Severe PE

0.40

0.03

$0.17-0.91$

UPE urinary protein excretion, $B P$ Blood pressure in $\mathrm{mmHg}, P E$ Preeclampsia, $A K I$ Acute kidney injury, GD gestational diabetes f/u follow-up, $d$ days persistent hypertensive values $\geq 150 / 100 \mathrm{mmHg}$ at follow-up, but not persistent proteinuria or eGFR decline.

Data on kidney function in the first months to years after preeclampsia are limited. In the study by Shahbazian et al. [12] the mean estimated glomerular filtration rate (eGFR) after a mean follow up of 5.7 years was $108 \mathrm{ml} / \mathrm{min}(+/-14 \mathrm{ml} / \mathrm{min})$. Bar et al. found a mean creatinine of $79.2 \mu \mathrm{mol} / \mathrm{l}$ and $70.4 \mu \mathrm{mol} / \mathrm{l}$ after 2 to 4 months and after 3 to 5 years, respectively [19]. Shammas and others described no difference in renal function 10 years after hypertensive disorder in pregnancy in comparison to healthy women [17]. In our study, the mean eGFR at 6-months follow up was $110.7 \mathrm{ml} / \mathrm{min} / 1.73 \mathrm{~m}^{2}$. Only one woman had an eGFR below $60 \mathrm{ml} / \mathrm{min} / 1.73 \mathrm{~m}^{2}$. Thus, a reduced eGFR early after preeclampsia is uncommon. Our results correspond well with an analysis from Vikse et al. that showed a $0.1 \%$ risk of ESRD after preeclampsia after 30 years [4]. The improbability of chronic structural kidney disease is underlined by the absence of pathologic urine sediment findings in our study.

We arbitrarily defined kidney decline as a decrease in kidney function by $\geq 10 \mathrm{ml} / \mathrm{min} / 1.73 \mathrm{~m}^{2}$, which was present in 27 women. The clinical significance of this decline is difficult to interpret. Since physiologic glomerular hyperfiltration is still present at the end of pregnancy, the reported "decline" could really be a return to baseline before pregnancy. On the other hand, it was only present in a minority of patients and significantly associated with severe preeclampsia, both arguments against a physiological process. However, although a signifcant difference $(p<0.00)$ in medians in eGFR in women with a decline in eGFR $\left(103 \mathrm{ml} / \mathrm{min} / 1.73 \mathrm{~m}^{2}\right)$ and women without $\left(114 \mathrm{ml} / \mathrm{min} / 1.73 \mathrm{~m}^{2}\right)$ was present, both were within normal range. Furthermore, as mentioned above the risk of ESRD after preeclampsia is far lower than the $13 \%(27 / 197)$ of women with an 
eGFR delcine in our study, thus the clinical significance remains unclear.

Our study has several strengths. To the best of our knowledge, this is the largest study on short term sequelae of preeclampsia. Furthermore, information on urine sediments has not been reported in this setting before. Due to a standardized protocol for follow-up after preeclampsia at our clinic, a low number of patients were lost to follow-up. The collection of several baseline characteristics allowed for secondary analysis for risk factors.

There are also several limitations. Being designed as a cohort study, there is no control group as a reference. We did not have information on GFR during pregnancies, since there were no routine blood tests before preeclampsia symptoms occurred with mostly initiation of delivery short thereafter. An analysis on possible sociodemographic differences between the patients lost to follow-up and the patients included in our study would have been of interest, but was not possible due to unavailability of sociodemographic data. There seems to be a selection bias with a high incidence for severe preeclampsia (67\%), most likely due to our hospital being a tertiary center with referral of more complicated deliveries. Additionally, even though all patients with preeclampsia in our center are supposed to be referred for nephrology follow-up after 6 months, we cannot exclude that some patients with mild forms of preeclampsia were not referred for follow-up leading to a higher incidence of severe preeclampsia.

\section{Conclusion}

Given the high frequency of sequelae 6 months after preeclampsia, this study underlies the importance of close follow-up. To identify those women at risk for persistent symptoms, knowing what features of preeclampsia are associated with these short-term sequelae would be important. We identified age and gestational diabetes as risk factors for proteinuria and severe preeclampsia for a decline in eGFR. However, further studies are need to define the clinical relevance of these findings.

\section{Abbreviations}

CKD-EPI: Chronic kidney disease epidemiology collaboration; eGFR: Estimated glomerular filtration rate; ESRD: End-Stage Renal Disease; HELLP: Hemolysis, Elevated Liver Enzymes, Low Platelet; SD: Standard Deviation

\section{Availability of data and materials}

Data will not be shared to preserve medical confidentiality.

\section{Authors' contributions}

MG contributed to conception and design, collected, analyzed and interpreted the data and wrote the manuscript. IH was involved in critically revising the manuscript and gave approval to publish the manuscript. CM contributed to interpreting the data and gave approval to publish the manuscript. MD made major contributions to conception and design of the study and analyzing the data. He was a major contributor in writing the manuscript and gave approval of the manuscript to be published. All authors read and approved the final manuscript for publication.

\section{Ethics approval and consent to participate}

This study was approved by the Swiss Ethic Committee of northwest and central Switzerland as part of the swissethics association to be conducted under Art. 34 HFG, ART. 37-40 HFV of Swiss Federal Law waiving the need for consent.

\section{Competing interests}

The authors declare that they have no competing interests.

\section{Publisher's Note}

Springer Nature remains neutral with regard to jurisdictional claims in published maps and institutional affiliations.

\section{Author details}

${ }^{1}$ Clinic for Transplantation Immunology and Nephrology, University Hospital Basel, Petersgraben 4, 4031 Basel, Switzerland. 'Department of Gynaecology and Obstetrics, University Hospital Basel, Spitalstrasse 21, 4031 Basel,

Switzerland.

Received: 12 October 2017 Accepted: 30 April 2018

Published online: 21 May 2018

References

1. Abalos E, Cuesta C, Grosso AL, Chou D, Say L. Global and regional estimates of preeclampsia and eclampsia: a systematic review. Eur J Obstet Gynecol Reprod Biol. 2013;170:1-7. https://doi.org/10.1016/j.ejogrb.2013.05.005.

2. Vikse BE, Irgens $L M$, Bostad L, Iversen BM. Adverse perinatal outcome and later kidney biopsy in the mother. J Am Soc Nephrol. 2006;17:837-45. https://doi.org/10.1681/ASN.2005050492.

3. Wang I-K, Muo C-H, Chang Y-C, Liang C-C, Chang C-T, Lin S-Y, et al. Association between hypertensive disorders during pregnancy and endstage renal disease: a population-based study. CMAJ. 2013;185:207-13. https://doi.org/10.1503/cmaj.120230.

4. Vikse BE, Irgens LM, Leivestad T, Skjaerven R, Iversen BM. Preeclampsia and the risk of end-stage renal disease. N Engl J Med. 2008;359:800-9. https://doi.org/10.1056/NEJMoa0706790.

5. Chesley LC, Annitto JE, Cosgrove RA. American journal of obstetrics and gynecology, volume 124, 1976: the remote prognosis of eclamptic women. Sixth periodic report. Am J Obstet Gynecol. 2000;182 1 Pt 1:247. discussion 248. http://www.ncbi.nlm.nih.gov/pubmed/10649186. Accessed 14 Oct 2016

6. Sibai BM, el-Nazer A, Gonzalez-Ruiz A. Severe preeclampsia-eclampsia in young primigravid women: subsequent pregnancy outcome and remote prognosis. Am J Obstet Gynecol. 1986;155:1011-6. http://www.ncbi.nlm.nih. gov/pubmed/3777042. Accessed 14 Oct 2016

7. Fisher KA, Luger A, Spargo BH, Lindheimer MD. Hypertension in pregnancy: clinical-pathological correlations and remote prognosis. Medicine (Baltimore). 1981;60:267-76. http://www.ncbi.nlm.nih.gov/pubmed/7242320. Accessed 14 Oct 2016

8. Report of the National High Blood Pressure Education Program Working Group on high blood pressure in pregnancy. Am J Obstet Gynecol. 2000; 183:S1-22. http://www.ncbi.nlm.nih.gov/pubmed/10920346. Accessed 14 Oct 2016

9. Magee LA, Pels A, Helewa M, Rey E, von Dadelszen P. SOGC hypertension guideline committee. Diagnosis, evaluation, and management of the hypertensive disorders of pregnancy: executive summary. J Obstet Gynaecol Canada. 2014;36:575-6. http://www.ncbi.nlm.nih.gov/pubmed/25184972. Accessed 14 Oct 2016

10. Federführende Leitlinien der deutschen Gesellschaft für Gynäkologie und Geburtshilfe; Diagnostik und Therapie hypertensiver Schwangerschaftserkrankungen. 2013.

11. Berks D, Steegers EAP, Molas M, Visser W. Resolution of hypertension and proteinuria after preeclampsia. Obstet Gynecol. 2009;114:1307-14. https://doi.org/10.1097/AOG.0b013e3181c14e3e.

12. Shahbazian N, Shahbazian H, Ehsanpour A, Aref A, Gharibzadeh S. Hypertension and microalbuminuria 5 years after pregnancies complicated by pre-eclampsia. Iran J Kidney Dis. 2011;5:324-7. http://www.ncbi.nlm.nih. gov/pubmed/21876309. Accessed 14 Oct 2016

13. American College of Obstetricians and Gynecologists, Task Force on Hypertension in Pregnancy. Hypertension in pregnancy. Obstet Gynecol. 2013;122:1122-31. https://doi.org/10.1097/01.AOG.0000437382.03963.88. 
14. Severe Pre-eclampsia/Eclampsia, Management (Guideline No. 10A). R Coll Obstet Gynecol

15. Fulks M, Stout RL, Dolan VF. Urine protein/creatinine ratio as a mortality risk predictor in non-diabetics with normal renal function. J Insur Med. 2012;43:7683. http://www.ncbi.nlm.nih.gov/pubmed/22876411. Accessed 11 Oct 2017

16. Suzuki H, Watanabe Y, Arima H, Kobayashi K, Ohno Y, Kanno Y. Short- and long-term prognosis of blood pressure and kidney disease in women with a past history of preeclampsia. Clin Exp Nephrol. 2008;12:102-9. https://doi. org/10.1007/s10157-007-0018-1.

17. Shammas AG, Maayah JF. Hypertension and its relation to renal function 10 years after pregnancy complicated by pre-eclampsia and pregnancy induced hypertension. Saudi Med J. 2000;21:190-2. http://www.ncbi.nlm.nih. gov/pubmed/11533780. Accessed 21 Oct 2016

18. Nisell H, Lintu H, Lunell NO, Möllerström G, Pettersson E. Blood pressure and renal function seven years after pregnancy complicated by hypertension. $\mathrm{Br}$ J Obstet Gynaecol. 1995;102:876-81. http://www.ncbi.nlm.nih.gov/pubmed/ 8534622. Accessed 14 Oct 2016

19. Bar J, Kaplan B, Wittenberg C, Erman A, Boner G, Ben-Rafael Z, et al. Microalbuminuria after pregnancy complicated by pre-eclampsia. Nephrol Dial Transplant. 1999;14:1129-32. http://www.ncbi.nlm.nih.gov/pubmed/ 10344350. Accessed 14 Oct 2016

20. Chua S, Redman CW. Prognosis for pre-eclampsia complicated by $5 \mathrm{~g}$ or more of proteinuria in 24 hours. Eur J Obstet Gynecol Reprod Biol. 1992;43: 9-12. http://www.ncbi.nIm.nih.gov/pubmed/1737613. Accessed 21 Oct 2016

Ready to submit your research? Choose BMC and benefit from:

- fast, convenient online submission

- thorough peer review by experienced researchers in your field

- rapid publication on acceptance

- support for research data, including large and complex data types

- gold Open Access which fosters wider collaboration and increased citations

- maximum visibility for your research: over $100 \mathrm{M}$ website views per year

At BMC, research is always in progress.

Learn more biomedcentral.com/submissions 